\title{
UTILIZAÇÃO DA MANIPUEIRA COMO FERTIRRIGANTE NA CULTURA DO GIRASSOL
}

\author{
Thiago Costa Ferreira ${ }^{1}$, Jose Thyago Aires Souza², Ana Lucia Araujo Cunha ${ }^{3}$ \\ ${ }^{1}$ Universidade Estadual Julio de Mesquita Filho, R. Dr. José Barbosa de Barros, 1780 - Jardim Paraiso, Botucatu, SP, ${ }^{2}$ Universidade Federal \\ da Paraiba - Campus II - Zona Rural - Areia, PB, ${ }^{3}$ Universidade Estadual da Paraiba - Campus II - Zona Rural - Lagoa Seca, PB.
}

*Autor para correspondência: ferreira_uepb@hotmail.com

RESUMO: 0 experimento foi conduzido em campo, no DAA/CCAA/UEPB, município de Lagoa Seca - PB. Objetivou-se estudar, o efeito da fertirrigação de cinco níveis de manipueira: 0, 125, 250375 e $500 \mathrm{~mL} /$ planta, sobre características produtivas e fitomassa seca da cultura do girassol (Helianthus annuus L.), cultivar Crioula. Usou-se 0 delineamento experimental de blocos ao acaso. Para análise foram computados os dados referentes produção total (PS), fitomassa seca dos capítulos (FCA), fitomassa seca das sementes e capítulos (FSC), fitomassa seca do caule e das folhas (FCF) e fitomassa seca total (FT). Apresentando efeito quadrático para as variáveis FCA, FSC, FCF e FT. A manipueira é eficaz na fertirrigação do girassol.

Palavras-chave: Fertilização, Agricultura Orgânica, Helianthus annuus.

\section{USE OF MANIPUEIRA IN CULTURE AS FERTIRRIGANTE SUNFLOWER}

ABSTRACT: The experiment was conducted in the field, the DAA/CCAA/UEPB, Lagoa Seca - PB. The objective was to study the effect of fertigation five levels Manipueira: 0, 125, 250, 375 and $500 \mathrm{~mL} /$ plant on productive traits, and dry weight of dried sunflower crop (Helianthus annuus L.) cultivar Creole. We used the experimental design of randomized blocks. To analyze the data regarding total production (PS), dry weight of Chapters (FCA), dry mass of seeds and chapters (FSC), dry weight of stem and leaves (FCF), and total dry matter (FT) were computed. The results there were a quadratic effect for FCA, FSC, FCF and FT variables. Manipueira is effective in fertigation sunflower.

Key words: Fertilization, Organic Agriculture, Helianthus annuus.

\section{INTRODUÇÃO}

A adubação consiste no reestabelecimento da fertilidade natural de uma área de plantio provendo as culturas agrícolas nutrientes que estariam em falta nos locais de cultivo, sendo levado em consideração, diferentes aspectos abióticos e bióticos (Primavesi, 2000), principalmente em áreas bastante desgastadas pelo uso antrópico intensivo e irracional dos recursos naturais, podendo estas ser adubadas com fertilizantes de origem orgânica, utilizando materiais comuns e de baixo custo ao produtor rural (Malavolta e Alacarde, 2002).

$A$ adubação orgânica pode ser realizada fornecendo aos vegetais nutrientes por meio da fertirrigação; prática que consiste na aplicação de compostos líquidos ou dissolvidos por meio do sistema de irrigação, diretamente no solo ou sob os tecidos vegetativos; apresentando assim, vantagens quando comparado com os adubos orgânicos sólidos, pois pode ser distribuída uniformemente sob a superfície do vegetal, facilitando assim a absorção e translocação dos compostos químicos que constituem um fertilizante (Castro, 2003).

Partindo do princípio que o adubo orgânico deve apresentar as características acima citadas, podemos citar a utilização da manipueira, fluido orgânico bastante comum nas áreas de produção familiar no Nordeste Brasileiro (Ferreira et al., 2010; Souza et al., 2010), que é um subproduto da produção de farinha de mandioca (Manihot esculenta C.) (Euphorbiaceae). A manipueira apresenta-se como suspensão aquosa, rica em substâncias benéficas aos vegetais, com uma 
quantidade elevada de fósforo. Atualmente trabalhos científicos apontam este líquido como uma boa fonte de adubação orgânica para os cultivos comerciais (Borszowskei et al., 2009; Tlumaski et al., 2009).

A cultura do girassol (Helianthus annuus L.) apresenta grande importância econômica mundial como fonte de energia alternativa, cultivada em todos os continentes, com uma área de aproximadamente 18 milhões de hectares, sendo a quarta oleaginosa em produção de grãos e a quinta em área cultivada (Silveira et al., 2009). Esta Asteraceae compõe o programa do biodiesel brasileiro, além de apresentarse como produtora de óleo com excelente qualidade, e vem sendo utilizada na formação de silagem, para alimentação animal com elevado teor protéico, superando inclusive a do milho e a do sorgo, sendo uma boa alternativa para o sistema de rotação de culturas (Silva et al., 2010).

Devido às características de resistência à seca e a baixa temperatura, o girassol apresenta ampla adaptabilidade em diferentes regiões agrícolas, proporcionando perspectivas para expansão de sua área cultivada em diversas regiões do Brasil, com diferentes tipos de manejo agrícola (Lima et al., 2010).

Com base na escassez de material produzido sobre 0 assunto, este trabalho tem como objetivo principal estudar a adubação orgânica baseada na utilização da manipueira no cultivo do girassol.

\section{MATERIAL E MÉTODOS}

0 experimento foi realizado entre os meses de dezembro de 2010 e março de 2011, em área de campo, pertencente ao Departamento de Agroecologia e Agropecuária (DAA) da Universidade Estadual da Paraíba, Campus II, Lagoa Seca, situado na mesorregião do Agreste da Paraíba, com as seguintes coordenadas geográficas: latitude $7^{\circ} 09^{\prime} \mathrm{S}$; longitude $35^{\circ} 52^{\prime} \mathrm{W}$, o clima da região é caracterizado como tropical úmido (As), com temperatura média anual em torno de $22^{\circ} \mathrm{C}$, sendo a mínima de $18^{\circ} \mathrm{C}$ e a máxima de $33^{\circ} \mathrm{C}$; altitude média de $634 \mathrm{~m}$ metros em relação ao nível do mar.

De acordo com a análise química realizada pelo Laboratório de Irrigação e Salinidade (LIS), pertencente a Universidade Federal de Campina Grande, o solo presente na localidade do ensaio apresentou as seguintes características indicadas pela análise química: $\mathrm{pH}\left(\mathrm{H}_{2} \mathrm{O}\right)=5,6, \mathrm{Ca}^{2+}=2,4 \mathrm{cmolc} . \mathrm{dm}^{3}, \mathrm{Mg}^{2+}$ $=1,1 \mathrm{cmol}_{\mathrm{c}} \cdot \mathrm{dm}^{-3}, \mathrm{Na}^{+}=0,27 \mathrm{cmol}_{\mathrm{c}^{-}} \mathrm{dm}^{-3}, \mathrm{SB}=3,81 \% ; \mathrm{H}^{+}$ $+\mathrm{Al}^{3+}=4,46 \mathrm{cmol}_{\mathrm{C}^{\prime}} \cdot \mathrm{dm}^{-3} ; \mathrm{T}=8,87 ; \mathrm{V} \%=46,07 ; \mathrm{Al}^{3+}=0,05$ $\mathrm{cmol}_{\mathrm{c}} \cdot \mathrm{dm}^{-3} ; \mathrm{MO}=12,55 \mathrm{~g} \cdot \mathrm{kg}^{-1}$ e $\mathrm{P}^{+}=12,52 \mathrm{cmol}_{\mathrm{c}} \cdot \mathrm{dm}^{-3}$, na qual o local de coleta apresenta o solo classificado como Neossolo Regolítico (Embrapa, 2013).

0 local experimental utilizado compreendia uma área de $42,0 \mathrm{~m}^{2}$, demarcada por 5 parcelas de 2,0 x 4,2 m, totalizando uma área de $8,4 \mathrm{~m}^{2}$ cada, distantes $1 \mathrm{~m}$ entre si, apresentando 24 covas de $30 \mathrm{x}$ $30 \times 30 \mathrm{~cm}$, com o espaçamento por covas de $0,7 \times$ $0,5 \mathrm{~m}$; em que dentro de cada parcela encontravamse quatro repetições, compostas por seis plantas cada. Foi cultivada o girassol variedade Crioula, obtida no comércio da cidade de Campina Grande - PB.

Foi realizada uma adubação de fundação com quinze dias de antecedência à semeadura, com 0,5 $\mathrm{kg} \cdot \mathrm{m}^{-2}$ de esterco bovino curtido por três meses em local sombreado, colocando uma camada $5 \mathrm{~cm}$ de solo do local sob o esterco, para que as sementes que foram plantadas não entrassem em contato direto. 0 esterco bovino apresentava a seguinte caracterização química percentual correspondente a um quilo de material analisado: MO: 7,0; cinzas: 3; N: 1,5; P: 0,9; K: 1,9; realizada pelo Laboratório de Irrigação e Salinidade da Universidade Federal de Campina Grande.

Em campo foi utilizado o delineamento em blocos casualizados (DBC), no qual constava de cinco tratamentos compostos por volumes pulverizados nos vegetais: T1- $0 \mathrm{~mL}$ de manipueira/planta; T2- 125 $\mathrm{mL}$ de manipueira/planta; T3- $250 \mathrm{~mL}$ de manipueira/ planta; T4 -375 mL de manipueira/planta e T5- $500 \mathrm{~mL}$ de manipueira/planta, na qual os tratamentos constava de três pulverizações de manipueira (30, 60 e 75 dias de semeadura), as dosagens foram adaptadas de Araújo (2010).

A manipueira foi previamente coletada em uma casa de farinha na região do experimento, colocada em repouso por pelo menos uma semana, em recipientes plásticos hermeticamente fechados, esta apresentava as seguintes caracterizações químicas percentuais (\%) para um litro de solução analisada: MO: 5,$0 ; \mathrm{N}: 2,7 ; \mathrm{P}$ : 0,$54 ; \mathrm{K}: 2,34 ;$ A proporção de diluição da manipueira foi de $50 \%$ na quantidade aplicada em cada tratamento.

As variáveis mensuradas foram medidas e seus resultados extrapolados para kg.ha-1, sendo elas: Produtividade de sementes (PS): peso em kg.ha-1 das sementes, obtida pela pesagem dos aquênios retirados 
diretamente dos capítulos; Fitomassa seca dos capítulos (FCA): peso seco dos capítulos em kg.ha-1 ${ }^{-1}$ somente a estrutura do capítulo sem as sementes; Fitomassa seca das sementes e capítulos (FSC): peso soma do peso obtido das sementes e capítulos em kg.ha-1- Fitomassa seca das folhas e do caule (FCF): peso seco das folhas e dos caules em kg; Fitomassa seca total (FT): fitomassa seca de toda a produção vegetativa; obtidos pela secagem dos materiais vegetativos coletados no final do ciclo cultural, acondicionados em estufa ventilada, por cerca de três dias a uma temperatura constante de $64^{\circ} \mathrm{C}$, e posterior pesagem em balança de precisão.

Sendo estes dados submetidos ao Teste $\mathrm{F}$, a 5 e $1 \%$ de probabilidade, e nos casos em que houve diferenças significativas entre os tratamentos, procedeuse a análise da regressão das variáveis, utilizando-se o software ASSISTAT, segundo a metodologia proposta por Silva e Azevedo (2009).

\section{RESULTADOS E DISCUSSÃO}

As plantas avaliadas apresentaram-se injuriadas (lesão física), pela ação de agentes químicos presentes na manipueira, pois fisiologicamente a aplicação de manipueira pode ter lesado os tecidos do sistema aéreo dos vegetais em questão (FIGURA 1). Houve efeito significativo entre os tratamentos, em função das doses crescentes de manipueira, na qual se ajustaram satisfatoriamente ao modelo quadrático, quando submetidos à análise de regressão polinomial.

Figura 1. Tecido foliar injuriado após a fertirrigação com manipueira

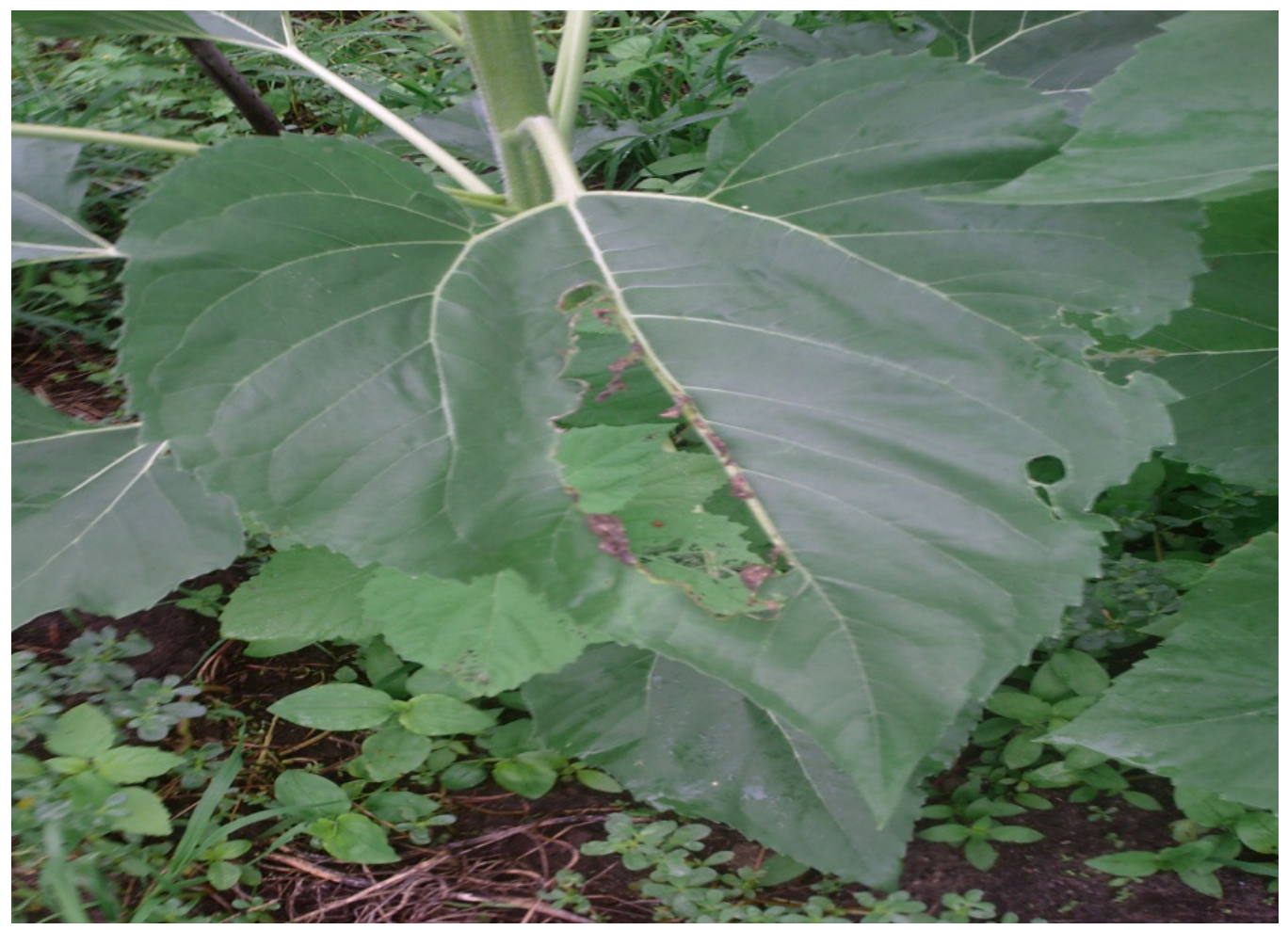

Os resultados apresentados acerca do aparecimento de injurias foliares nas plantas de girassol estudadas corroboram com os encontrados por Ferreira et al. (2010), que constataram o aparecimento de injúrias e mortes em mudas mamoneira, variedade BRS Nordestina, cultivadas em ambiente protegido, após a fertirrigação com manipueira diretamente do substrato das mudas.

Porém, para a variável fitomassa seca dos caules e folhas não respondeu significativamente a análise de regressão, sendo seus resultados não significativos para ambos os modelos matemáticos utilizados. Ainda para esta variável, a dosagem de $0 \mathrm{~mL}$ de manipueira promoveu o peso absoluto de 1364,32 $\mathrm{kg} \cdot \mathrm{ha}^{-1} \mathrm{em}$ meio às outras dosagens de manipueira. Apresentando resultados significativos para algumas variáveis em estudo, diferentemente de Ungaro et al. (2000) e Lima et al. (2010), que encontraram resultados significativos em seus experimentos de campo com girassóis de diferentes variedades, em localidades diferentes do território brasileiro (TABELA 1). 
Tabela 1. Variáveis de Acúmulo de Fitomassa em Helianthus annuus fertirrigado com Manipueira no agreste Paraibano - Lagoa Seca, PB

\begin{tabular}{c|c|c}
\hline VARIÁVEL & EQUAÇÃO & $\mathbf{R}^{2}$ \\
\hline Produção total & $Y=-0,00006 x^{2}-0,789 x+897,83$ & 0,78 \\
Fitomassa seca dos capítulos & $Y=0,000013 x^{4}-, 001 x^{3}+0,35 x^{2}-34,36 x+2077,38$ & 0,99 \\
Fitomassa seca das sementes e capítulos & $Y=0,000011 x^{4}-, 0011 x^{3}+0,40 x^{2}-40,97 x+3011,9$ & 1 \\
Fitomassa seca total & $Y=-0,81 x^{2}-81,95 x+6023,80$ & 0,69 \\
\hline
\end{tabular}

A variável produtividade de sementes apresentou os seguintes resultados médios em kg.ha-1 de 934,52; 699,40; 761,90; 702,38 e 467,26; para as dosagens de $0 ; 125 ; 250 ; 375$ e $500 \mathrm{~mL}$ de manipueira por planta, respectivamente. Na Tabela 1 , está representada sua análise de regressão polinomial, a qual apresentou efeito quadrático grau significativo $(p<0,01)$, obtendo o peso seco máximo de $934,520 \mathrm{~kg} \cdot \mathrm{ha}^{-1}$ com aplicação da dosagem de $0 \mathrm{~mL}$ de manipueira.

Segundo o modelo teórico, a dosagem de 1166,36 mL de manipueira obterá 1,63 kg.ha-1 de aquênios, comprovado pelo $78 \%$ pela presença de manipueira. Acosta (2009), obteve uma produção de grãos de girassol em condições irrigadas no município de Apodi- RN equivalente a $2260 \mathrm{~kg} \mathrm{ha}^{-1}$, e Silva et al. (2007) experimentaram o cultivo de girassol irrigado com diversas lâminas no município de Lavras - MG, cuja produtividade de grãos atingiu 2863,12 kg.ha-1. ambos demonstram uma produtividade mais acentuada que a relatada neste trabalho.

A variável fitomassa seca dos capítulos apresentou os seguintes resultados médios em kg.ha-1 de 2077,381; 1392,857; 2380,95; 1473,21 e 922,619; para as dosagens de 0; 125; 250; 375 e $500 \mathrm{~mL}$ de manipueira por planta, respectivamente. $\mathrm{Na}$ Tabela 1, está representada sua análise de regressão polinomial, a qual apresentou efeito exponensial de quarto grau significativo $(p<0,01)$, obtendo o peso seco máximo de $2380,95 \mathrm{~kg} \cdot \mathrm{ha}^{-1} \mathrm{com}$ aplicação da dosagem de $250 \mathrm{~mL}$ de manipueira, assim apresentando um aumento percentual de $32,03 \%$, quando comparado com a testemunha.

Segundo o modelo teórico, a dosagem de $61,71 \mathrm{~mL}$ de manipueira obterá $0,4 \mathrm{~kg} \cdot \mathrm{ha}^{-1}$ de capítulos, comprovado pelo $99 \%$ pela presença de manipueira. A produção vegetativa descrita por Arruda Filho et al. (2007), indicam que a variedade IACUruguai, cultivada em Latossolo vermelho amarelo, no município paraibano de Areia, com crescentes níveis de calagem e adubação fosfatada, promoveu um incremento substancial de fitomassa seca de cerca de $50 \%$ em relação à testemunha, valor acima do encontrado neste trabalho.

Já a variável fitomassa seca das sementes e capítulos, apresentou os seguintes resultados médios em kg.ha-1 de 2681,6; 2083,33; 3422,61; 2470,6 e 1330,35; para as dosagens de 0; 125; 250; 375 e 500 $\mathrm{mL}$ de manipueira por planta, respectivamente. $\mathrm{Na}$ Tabela 1, está representada sua análise de regressão polinomial, a qual apresentou efeito exponencial de quarto grau significativo a $1 \%$ para o Teste $F$, com o peso seco máximo de 3432,00 kg.ha-1 ${ }^{-1}$, através da aplicação de $250 \mathrm{~mL}$ de manipueria, promovendo um aumento percentual de $132,55 \%$, quando comparado com a testemunha. A dosagem de $74,84 \mathrm{~mL}$ de manipueira, obterá, segundo o modelo teórico, 21951,48 kg.ha-1 de sementes e capítulos, comprovado pelo $99 \%$ pela presença de manipueira.

A variável fitomassa seca total apresentou os seguintes resultados médios em kg.ha-1 de 22541,7; 27978,6 ; 22809,5; 28017,90 e 16694,0; para as dosagens de $0 ; 125 ; 250 ; 375$ e $500 \mathrm{~mL}$ de manipueira por planta, respectivamente. $\mathrm{Na}$ Tabela 1, está representada sua análise de regressão polinomial, a qual apresentou efito quadrático $(p<0,01)$ significativo, sendo que o peso seco máximo obtido foi de 28017,9 $\mathrm{kg} \cdot \mathrm{ha}^{-1} \mathrm{com}$ aplicação de manipueira da dosagem de $375 \mathrm{~mL}$ de manipueria, com um aumento percentual de $124,96 \%$ quando comparado com a testemunha.

Para a dosagem de $0,2 \mathrm{~mL}$ de manipueira, obteve-se, segundo o modelo teórico, 4561,50 $\mathrm{kg} \mathrm{ha}^{-1}$ de fitomassa seca total, comprovado pelo $96 \%$ pela presença de manipueira. Ungaro et al. (2000) encontraram resultados de matéria seca de total de 84,7 g.planta ${ }^{-1}$ para a planta de girassol IACAnhandy em condições de campo; Folini et al. (2007) adubando o girassol com compostos químicos a base 
de Boro, aplicadas via foliar, promoveu incremento na produção de fitomassa seca total e na produção de grãos de girassol.

Foloni et al. (2010), observaram que o girassol cultivado em casa de vegetação, adubado com diferentes fontes de Boro, respondeu satisfatoriamente a adubação empregada, e assim, possibilitou um acréscimo de fitomassa seca nas sementes e tecidos fotossínteticos, em relação a testemunha não adubada. Resultado semelhante ao encontrado por Ungaro et al. (2000), comprovou que girassóis de diversas variedades (IAC-Anhandye, VNIIMK e o híbrido Contisol 621), cultivadas no município de Monte Alegre do SulSP, apresentaram diferenciações entre si, no que se diz a fitomassa seca, haja vista as diferenças fenotípicas e de época de plantio.

Ungaro et al. (2000) encontraram resultados de matéria seca de total de 84,7 g.planta ${ }^{-1}$ para a planta de girassol IAC-Anhandy em condições de campo; Folini et al. (2007) adubando o girassol com compostos químicos a base de Boro, aplicadas via foliar, promoveu incremento na produção de fitomassa seca total e na produção de grãos de girassol.

A análise da regressão do experimento demonstra 0 indíce $R^{2}$ em níveis satisfatório segundo os parâmetros propostos por Banzatto e Kronka (1992), podendo então ser efetuada uma boa análise dos resultados obtidos (Tabela 1).

A adubação orgânica interfere positivamente na atividade biológica do solo, haja vista o aumento na matéria orgânica, promovendo assim uma complexa rede de relações entre diversos seres existentes na localidade, através da promoção de um habitat favorável, que propõe então um equilíbrio ecológico buscado pela agricultura de base ecológica (Primavesi, 2000).

O girassol é uma Asteraceae que responde bem aos estímulos fisiológicos promovidos pela adubação orgânica, apresentando também caráter reciclador de nutrientes presentes nas camadas do perfil do solo, pois seu aparelho radicular se estende por uma faixa considerável do solo trazendo para a superfície inúmeros nutrientes que outrora foram disponibilizados ao solo através da adubação antrópica ou natural, servindo como ótima reserva de nutrientes para o solo cultivado (Ungaro et al., 2000; Folini et. al 2010).

Desta forma, pode-se concluir que: a aplicação da manipueira favorece o acúmulo de fitomassa seca na cultura do girassol, sendo eficaz na produção de sementes e outros tecidos vegetais; a dosagem de 250 $\mathrm{mL}$ de manipueira por planta de girassol favorece o maior acúmulo de fitomassa seca para a variável fitomassa seca das folhas e do caule e a dosagem de $375 \mathrm{~mL}$ de manipueira por planta proporciona um maior para as variáveis produtividade em sementes, fitomassa seca dos capítulos, fitomassa seca semente com capítulos e fitomassa seca total, obtendo incrementos acima de $150 \%$ em relação à testemunha.

\section{REFERÊNCIAS BIBLIOGRÁFICAS}

ACOSTA, F. J. Consumo hídrico da cultura do girassol irrigada na região da Chapada do Apodi - RN. Dissertação de Mestrado, Universidade Federal de Campina Grande, Campina Grande, 2009.

ARRUDA FILHO, N. T.; OLIVEIRA, F.A.; SILVA, I. F.; OLIVEIRA, A. P. Aplicação de fósforo e calcário em um Latossolo: efeito sobre características produtivas da cultura do girassol (Helianthus annuus L.). Revista Verde, 2008, 3, 21 -26.

BANZATTO, D.A.; KRONKA, S.N. Experimentação Agrícola / David Arisvaldo Banzatto e Sérgio do Nascimento Kronka. Jaboticabal, FUNEP, 1992.

BORSZOWSKEI, P.R.; MILLÉO, R.D.S.; AHRENS, D.C.; ROMANIW, J. Utilização de Manipueira como Adubo Natural Alternativo para a Cultura do Morangueiro (Fragaria $x$ ananassa Duch.). In: Congresso Brasileiro de Agroecologia. (6.: 2009: Curitiba, Paraná). Anais: ... - Curitiba. ABA, SOCLA, Governo do Paraná, 2009. p. 1-6. CD-ROOM.

Embrapa. Sistema Brasileiro de Classificação de Solos / Humberto Gonçalves dos Santos ... [et al.]. - 3 ed. rev. ampl. - Brasília, DF: Embrapa, 2013,

CASTRO, 2003. Apostila de Irrigação. Instituto de Pesquisas Hidráulicas - UFRGS, 2003.

FERREIRA, T. C.; LIRA, E. H. A. L; SOUZA, J.T.A; OLIVEIRA, S. J. C. Fitomassa seca epígea e hipógea de mudas de mamoneira (Ricinus communis L.) sob diferentes dosagens de manipueira. In: IV Congresso Brasileiro de Mamona e I Simpósio Internacional de 
Oleaginosas (2010 - João Pessoa). Anais ... / Editores Odilon Reny R. F. da Silva e Renato Wagner da C. Rocha - Campina Grande, PB: Embrapa Algodão, 2010.

FOLINI, J.S.S.; GARCIA, R.A.; CARDOSO, C.L. TEIXEIRA, J.P. GRASSI FILHO, H. Desenvolvimento de grãos e produção de fitomassa seca do girassol em função de adubações boratadas. Bioscience. Journal, 2010, 26, 2, 273-280.

LIMA, A.D; MARINHO, A.B.; DUARTE, J.M.L.; VIANA, T.V.A.; AZEVEDO, B.M.; CAMBOIM NETO, L.F. Efeito da adubação borácica na cultura do girassol. In: IV Congresso Brasileiro de Mamona e I Simpósio Internacional de Oleaginosas (2010 - João Pessoa). Anais ... / Editores Odilon Reny R. F. da Silva e Renato Wagner da C. Rocha - Campina Grande, PB : Embrapa Algodão, 2010.

MALAVOLTA, E.; ALACARDE, J.C. Adubos e adubações / E. Malavolta, F. Pimental-Gomes e J.C. Alacarde. - São Paulo: Nobel, 2002.

PRIMAVESI, A. Manejo Ecológico do solo: a agricultura em regiões tropicais / Ana Primavesi. - São Paulo: Nobel, 2002.

SILVA, F. DE A. S. E.; AZEVEDO, C. A. V. DE. Principal Components Analysis in the Software AssistatStatistical Attendance. In: WORLD CONGRESS ON COMPUTERS IN AGRICULTURE, 7, Reno-NVUSA: American Society of Agricultural and Biological Engineers, 2009.

SILVA, M.L.O.; FARIA, M.A.; MORAIS, A.R.;ANDRADE, G.P.; LIMA, E.M.C. Crescimento e produtividade do girassol cultivado na entressafra com diferentes lâminas de água. Revista Brasileira de Engenharia Agrícola e Ambiental, 2007, 11, 5, 482 - 488.
SILVA, S. D.; SOARES, C. S. S.; MAGALHÃES, I. D.; COSTA, F. E. C.; ALVES, G.M. R.; ALMEIDA, A. E. S. Desenvolvimento vegetativo do girassol sob diferentes espaçamentos In: IV Congresso Brasileiro de Mamona e I Simpósio Internacional de Oleaginosas (2010 - João Pessoa). Anais ... / Editores Odilon Reny R. F. da Silva e Renato Wagner da C. Rocha - Campina Grande, PB : Embrapa Algodão, 2010.

SILVEIRA, P. S.; PEIXOTO, C. P.; LIMA, V.P.; SILVA, A.P. P.; BLOISI, A. M.; BORGES, V. P. Acúmulo de Massa de Matéria Seca e Desempenho Produtivo de Girassol (Helianthus annuus L.) no Recôncavo Baiano In: Congresso Brasileiro de Agroecologia. (6.: 2009: Curitiba, Paraná). Anais:...- Curitiba. ABA, SOCLA, Governo do Paraná, 2009. p.1-5

SOUZA, J. T. A.; FARIAS, A. L.; OLIVEIRA, S. J. C.; NÁPOLES, F. A. M.; AZEVEDO, C. A. V. Controle agroecológico do ácaro branco (Polyphagotarsonemus latus, Banks), na fase inicial do pinhão manso (Jatropha curcas L.). In: IV Congresso Brasileiro de Mamona e I Simpósio Internacional de Oleaginosas (2010 - João Pessoa). Anais ... / Editores Odilon Reny R. F. da Silva e Renato Wagner da C. Rocha - Campina Grande, PB: Embrapa Algodão, 2010.

TLUMASKI, L.; BORSZOWSKEI, P.R.; MILLÉO, R.D.S.; AHRENS, D.C. Alternativas ecológicas para 0 enraizamento de estacas de videira (Vitis labrusca L.) cv. Bordô. In: Congresso Brasileiro de Agroecologia. (6.: 2009: Curitiba, Paraná). Anais:...- Curitiba. ABA, SOCLA, Governo do Paraná, 2009. p.1-5.

UNGARO, M. R. G.; NOGUEIRA, S. S. S.; NAGAI, V. Parâmetros fisiológicos, produção de aquênios e fitomassa seca de girassol em diferentes épocas de semeadura. Bragantia, 2000, 59, 2, 206-211. 